\title{
Equine Pasture Asthma in Brazil
}

\author{
Liana Villela de Gouvêa', Camila Bernardes' ${ }^{1}$, Michel José Sales Abdalla Helayel', Nayro Xavier de Alencar', \\ Maria Fernanda de Mello Costa² \& Daniel Augusto Barroso Lessa'
}

\begin{abstract}
Background: Summer Pasture Associated Obstructive Pulmonary Disease (SPAOPD), or Equine Pasture Asthma (EPA), has been described as an environmentally-induced respiratory disease that occurs during the warmer and more humid months, leading to reversible airway obstruction, persistent and non-specific airway hyper-responsiveness, and chronic neutrophilic airway inflammation. Exacerbation of clinical signs vary according to warm seasons and range from mild to severe episodes of wheezing, coughing, and laboured breathing, being highly debilitating to the equine. This report described two cases of Equine Pasture Asthma that showed clinical and environmental similarities with Summer Pasture Associated Obstructive Pulmonary Disease.

Cases: The patients were crossbreed geldings that have never been stabled and were used for cattle management in a farm in southeastern Brazil. They presented poor performance and a persistent cough for over 3 years. Initially, the respiratory signs were only observed after exercise but, over the years, it gradually progressed to being observed when the horses were at rest. Both animals had a history of regular deworming and were previously treated by other veterinarians with antibiotics, clenbuterol, and mucokinetics. Little improvement was noticed by the owner and the signs returned over time as treatment was often discontinued. Clinical findings were compatible with the grade 3 mucus classification as well as with score 2 for Severe Asthma. BALF cytology was done according to routine procedure. Animal 1 presented slides with free yeast, macrophages, and mucus with Curschmann's spiral and counting of $29.7 \%$ of neutrophils (NE), $43.7 \%$ of lymphocytes (LP), $25.3 \%$ of macrophages (MC) and $1.3 \%$ of eosinophils (EO). Animal 2 presented slides with phagocytized yeast, mucus and counting of $27 \%$ of NE, $38.5 \%$ of LP, $33 \%$ of MC and $1.5 \%$ of EO.

Discussion: Diagnostic findings were compatible with the clinical score 2 for Severe Asthma, where the animals presented frequent cough with periods of no coughing, nostrils flares in inspiration and exhalation, obvious abdominal flattening and "heave line", pulmonary auscultation with crackles, and scarce mucous nasal discharge. Our cytological findings also fall within the Severe Asthma classification, when the specific counting of 300 cells is equivalent to $\geq 20 \%$ of neutrophils on BALF analysis and the animal present increase in respiratory rate/effort at rest. Similar counts were found by other authors counting 200 cells, 300 cells, and 5 fields (of at least 100 cells) on a cytocentrifuge smear. The present report took place in a region of the Rio de Janeiro State, southeastern Brazil, which shows predisposing climatic characteristics similar to those described in previous SPAOPD reports. Yet, this very climate remains somewhat constant throughout the year, as seasonality in the Rio de Janeiro State is not as marked as in the Northern Hemisphere. Given this contrasting aspect, we believe that the term Equine Pasture Asthma, instead of SPAOPD, is more appropriate to describe the cases presented here. Also, to the best of the authors' knowledge, this is the first documented description in Brazil of Equine Pasture Asthma in animals that were never stabled or fed with hay. This documented evidence of a chronic respiratory condition consistent with Equine Pasture Asthma but little related to seasonal changes presents as a warning to other possible cases that might go unnoticed in equine herds in Brazil and in similar climates.
\end{abstract}

Keywords: horse, non-infectious respiratory disease, recurrent airway obstruction, heaves, neutrophilic airway inflammation. 


\section{INTRODUCTION}

Summer Pasture Associated Obstructive Pulmonary Disease (SPAOPD), or Equine Pasture Asthma (EPA) [17], formerly recurrent airway obstruction (RAO), has been described as an environmentally-induced respiratory disease that occurs during the warmer and more humid months, leading to reversible airway obstruction, persistent and non-specific airway hyper-responsiveness, and chronic neutrophilic airway inflammation. Exacerbation of clinical signs vary according to warm seasons, and range from mild to severe episodes of wheezing, coughing, and laboured breathing in a chronic state that is debilitating for the equine [4].

More recently [10], the term Severe Equine Asthma (SEA) syndrome was used to refer to affected pastured horses that had no access to hay nor straw, and whose clinical manifestations occurred between spring and early autumn with complete remission during the winter months.

The present report took place in a region of the Rio de Janeiro State, southeastern Brazil, which shows predisposing climatic characteristics similar to those described in previous SPAOPD reports [7$9,13,14,23,25,30]$, even though the climate in Rio de Janeiro State remains somewhat constant throughout the year. Given this contrasting aspect, we believe that the term Equine Pasture Asthma, instead of SPAOPD, is more appropriate to describe the cases presented here. Therefore, to the best of the authors' knowledge, this is the first documented description in Brazil of Equine Pasture Asthma in animals that were never stabled or fed with hay and should be a warning to other possible cases that might be unnoticed in equine herds in Brazil and in similar climates.

\section{CASES}

Case 1. A crossbred gelding aged 12 years, approximately $380 \mathrm{~kg}$, with a complaint of poor performance and persistent cough for over 3 years.

Case 2. A crossbred gelding aged 14 years, approximately $400 \mathrm{~kg}$, with a complaint of poor performance and persistent cough for over 3 years.

In June, 2019, both animals were presented for veterinary examination. None of them had never been stabled and were used for cattle management in the same farm. Besides the cattle, they had contact with one other horse with no respiratory symptoms. At the time of this case, the property (Figure 1), located in
Rio Bonito municipality $\left(-22.709^{\circ},-42.610^{\circ}\right.$ and $101 \mathrm{~m}$ of altitude), Rio de Janeiro State, Brazil, had pastures composed of perennial grasses (Brachiaria decumbens, B. humidicula, and Paspalum sp.). The horses grazed over these areas and were never fed with hay - a common feeding management practice in most extensive horse breedings in Brazil.

In both occurrences, the owner reported that the cough worsened from April to June, at the beginning of the dry season (autumn and early winter) in Southern Hemisphere. Initially, the respiratory signs were only observed after exercise but, over the years, it gradually progressed to being observed when the horses were at rest. Both animals had a history of regular deworming (ivermectin associated with praziquantel ${ }^{1}$ ) and were previously treated by other veterinarians with antibiotics, clenbuterol ${ }^{2}$, and mucokinetics (bromhexine ${ }^{3}$ ). Little improvement in clinical manifestations was noticed by the owner and the signs returned over time as treatment was often discontinued.

During physical examination, neither patients presented alteration in body temperature, hydration status, color of mucous membranes or cardiac rate, and there was also no enlargement of lymph nodes during palpation. Nevertheless, both animals had high respiratory rates at rest (28 and $32 \mathrm{bpm}$, respectively), dyspnoea associated with abnormal lung sounds (crackles), and increased resonant sounds in percussion. Spontaneous cough, dry secretion around the nostrils, and a marked line on the lower lateral abdominal area due to muscle contraction during respiratory effort (Heave line, Figure 2) were also observed. These clinical findings are compatible with the clinical score 2 described by Davis \& Sheats [13].

The preliminary diagnostic procedure included a complete blood count, plasma fibrinogen and serum biochemistry tests as well as faecal egg counts. All results were within normal limits, and specific examination and collection of respiratory samples were proceeded in both patients.

All evaluation and sample processing were performed according to the Consensus guidelines [10] as follows. Tracheobronchoscopy (Figure 3) was conducted with an Olympus CF-10L colonoscope ${ }^{4}$, proceeded by bronchoalveolar lavage (BAL) using an equine silicone BAL catheter ${ }^{5}$ [SurgiVet ${ }^{\circledR}$ ], following the technique described by Couetil et al. [10]. For both procedures, the animals were sedated with $0.5 \mathrm{mg} / \mathrm{kg}$ 
of intravenous $10 \%$ xylazine chlorhydrate ${ }^{6}$ [Sedazine ${ }^{\circledR}$ ] associated with $0.02 \mathrm{mg} / \mathrm{kg}$ of intravenous butorphanol tartrate $^{7}\left[\right.$ Torbugesic $^{\circledR}$ ]. In addition, topical anaesthesia of the lower respiratory tract was achieved by instillation of $0.5 \%$ lidocaine $^{8}\left[\right.$ Lidovet $\left.^{\circledR}\right]$ before the BAL procedure. BAL fluid (BALF) was obtained through the infusion and immediate aspiration of $250 \mathrm{~mL}$ of warm 0.9 wt. \% $\mathrm{NaCl}$ solution, of which approximately $150 \mathrm{~mL}(60 \%)$ were recovered.

These exams revealed excessive tracheal mucus equivalent to the grade 3 classification of Gerber $e t$ al. [18], and oedema of the tracheobronchial bifurcation (carina). After endoscopy and BALF collection, samples were taken to the laboratory where slides were prepared by cytocentrifugation ${ }^{9}$ [Cytopro $7620^{\circledR}$ ] for $5 \mathrm{~min}$ at $110 \mathrm{x} g$ and stained with Romanowsky ${ }^{10}$ and Giemsa ${ }^{10}$ stains for differential cell counts (300 cells counted at $1000 \mathrm{x}$ magnification). Cytologic findings are illustrated in Figures 4 and 5. Animal 1 presented slides with free yeast, macrophages, and mucus with Curschmann's spiral and counting of $29.7 \%$ of neutrophils (NE), $43.7 \%$ of lymphocytes (LP), $25.3 \%$ of macrophages (MC) and $1.3 \%$ of eosinophils (EO). Animal 2 presented slides with phagocytized yeast, mucus, and counting of $27 \%$ of NE, $38.5 \%$ of LP, $33 \%$ of MC and $1.5 \%$ of EO.

Equine Pasture Asthma was diagnosed based on clinical history and signs, and supported by abnormal BALF cytology. Therefore, as primary management measure, the owner was advised to relocate the patients to another pasture since removal of exposure source is sometimes enough to cause improvement of clinical signs. This intervention was not possible due to farm logistics. Both animals were treated with triamcinolone acetonide ${ }^{11}$ [0.09 mg/kg IM, single dose] and Clenbuterol $^{2}[0.8 \mu \mathrm{g} / \mathrm{kg}$ PO, BID for 2 days, followed by $0.16 \mu \mathrm{g} / \mathrm{kg}$ PO, BID for another 13 days] [12]. After the initial pharmacological treatment, Omega 3 docosahexaenoic acid ${ }^{12}$ (DHA) PO was prescribed for 60 days at $1.5 \mathrm{~g} /$ day $(3.0 \mathrm{mg} / \mathrm{kg} /$ day $)$ [26].

The animals were not relocated to a different pasture, despite veterinary recommendation. Overall improvement of the clinical complaint was not reported by the owner, who decided to retire both animals from cattle management, since work effort could worsen their clinical condition. Treatment was also discontinued recurrently due to its cost being a limiting factor for the owner.

\section{DISCUSSION}

In Brazil, Severe Equine Asthma (SEA) syndrome has been described in stabled horses from the Southeastern region, including the states of Rio de Janeiro [1,21] and São Paulo [16]. In the present case report, diagnosis of Pasture Asthma was confirmed through respiratory examination and findings compatible with the literature [25]. Additional findings were made via tracheal endoscopy - revealing excessive tracheal mucus (mucous score 3 ) - and bronchoalveolar lavage fluid (BALF) cytology [10].

According to the last Consensus of the American College of Veterinary Internal Medicine [10], horses with severe equine asthma in the form of SPAOPD exhibit marked lower airway inflammation and obstruction associated with frequent coughing, increased respiratory effort at rest, and exercise intolerance. Both animals in this report presented all these signs over the course of three years. The specific findings of Davis \& Sheats [13], who analysed the syndrome's characteristics during seasonal changes in a herd of pastured teaching horses, produced a score to identify the severity of Equine Asthma based on clinical signs and BALF cytology. In that sense, our diagnostic findings fit the clinical score 2 (from 0 to 3 ) for Severe Asthma [13], where the animal present frequent cough with periods of no coughing, nostrils flares in inspiration and exhalation, obvious abdominal flattening and "heave line" (Figure 2), pulmonary auscultation with crackles, and scarce mucous nasal discharge.

The cytological findings of our reported cases also fall within the Severe Asthma classification [13], when the specific counting of 300 cells is equivalent to $\geq 20 \%$ of neutrophils on BALF analysis and the animal present increase in respiratory rate/effort at rest. Within this criterion, normal cytological findings are stated as: $\leq 6 \%$ neutrophils, $\leq 2 \%$ mast cells, and $\leq 1 \%$ eosinophils. Similar counts were found by other authors counting 200 cells [9], 300 cells [28], and 5 fields (of at least 100 cells) on a cytocentrifuge smear [11]. Our data are also compatible with a published result [9] of BALF analysis on SPAODP horses that shows medians of $65 \%$ neutrophils, $28.5 \%$ lymphocytes, $10.5 \%$ macrophages, and $0 \%$ of eosinophils.

The presence of neutrophilic inflammation (20-70\% of total cell count) is also indicative of lower airway inflammation and differentiates horses with heaves from horses with eosinophilic pneumonitis, fun- 


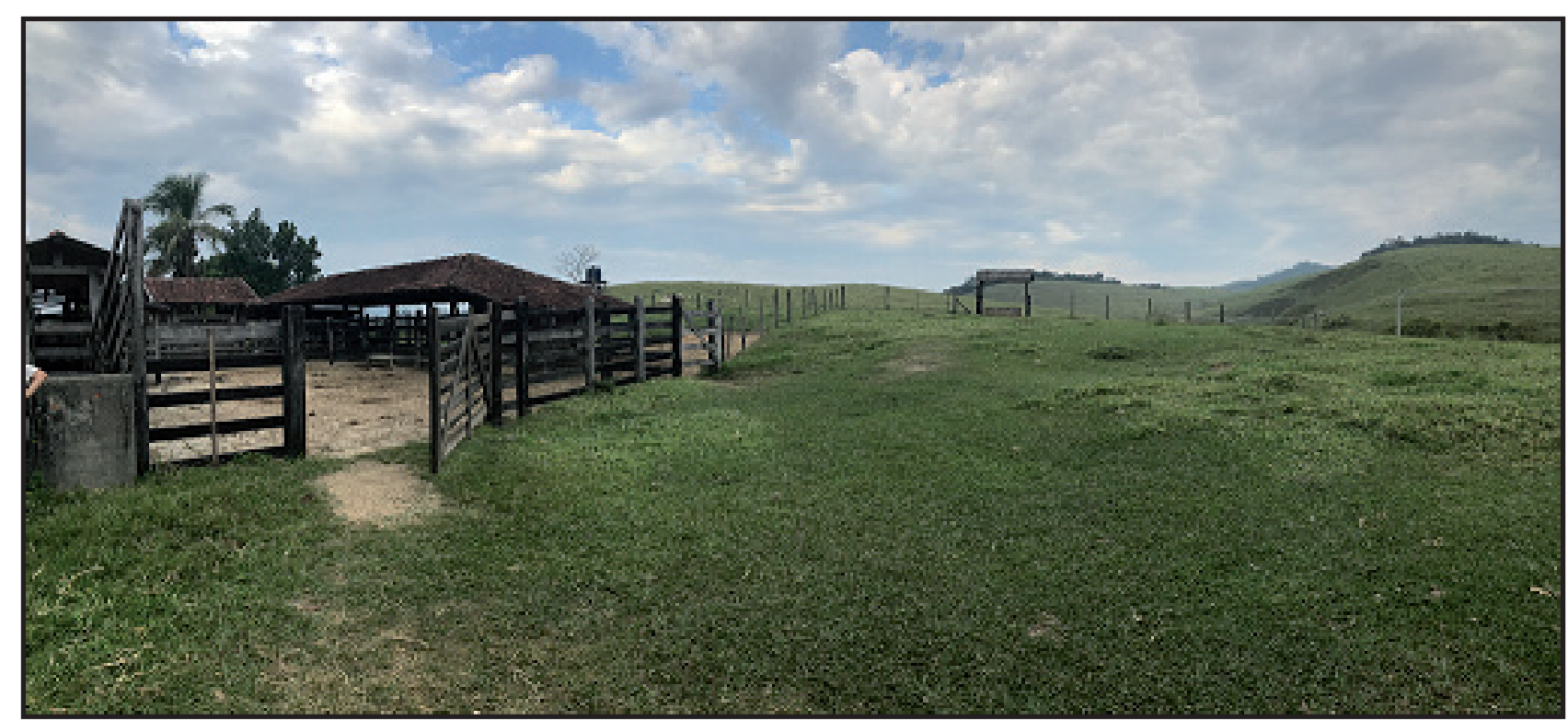

Figure 1. Farm with pasture and cattle management structure, located in Rio Bonito, state of Rio de Janeiro, Brazil.

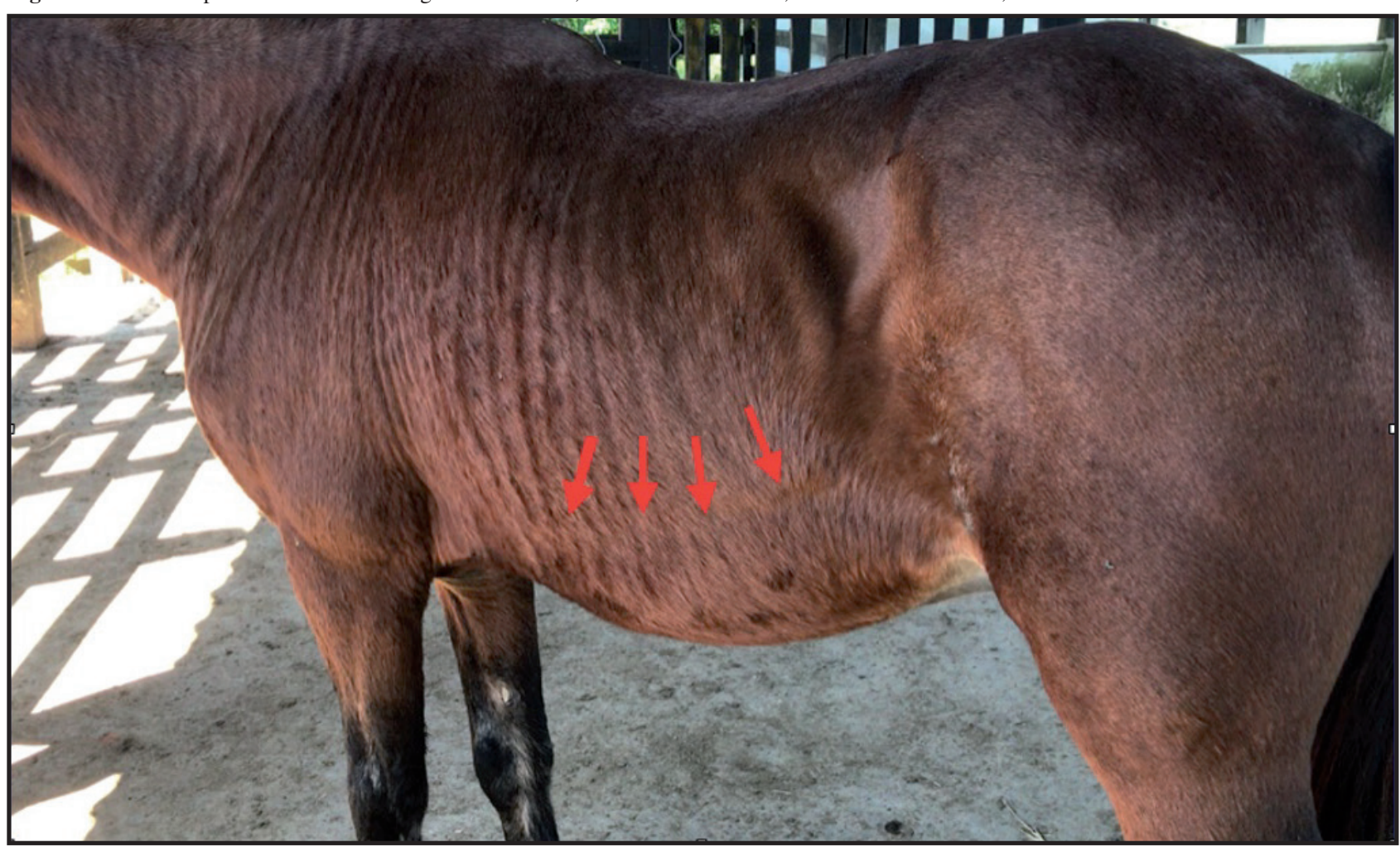

Figure 2. Patient (case 2) showing a characteristic heave line (red arrow).

gal pneumonia, or lungworm infestation [29]. When it comes to lungworm infections, chronic coughing, and not dyspnoea, appears as the main clinical feature, in addition to pulmonary eosinophilia and positive response to anthelmintic drugs [25]. It is also possible to observe necrotic debris in cytopathological findings of parasitic pneumonitis [15]. Yet, the animals of our study were regularly dewormed with ivermectin and praziquantel as part of the farm's management. They showed dyspnoea as a primary sign and no debris or eosinophilia were detected on their cytological analyses.

Another finding during our BALF analysis were Curschmann's spirals (Figure 5), which are casts composed of inspissated viscous, thick mucus that form plugs in the small bronchioles. As previously described by other authors $[2,19,22,24,32]$, Curschmann's spirals are recurrently found in horses with chronic inflammatory lung disease, corroborating our diagnosis. 


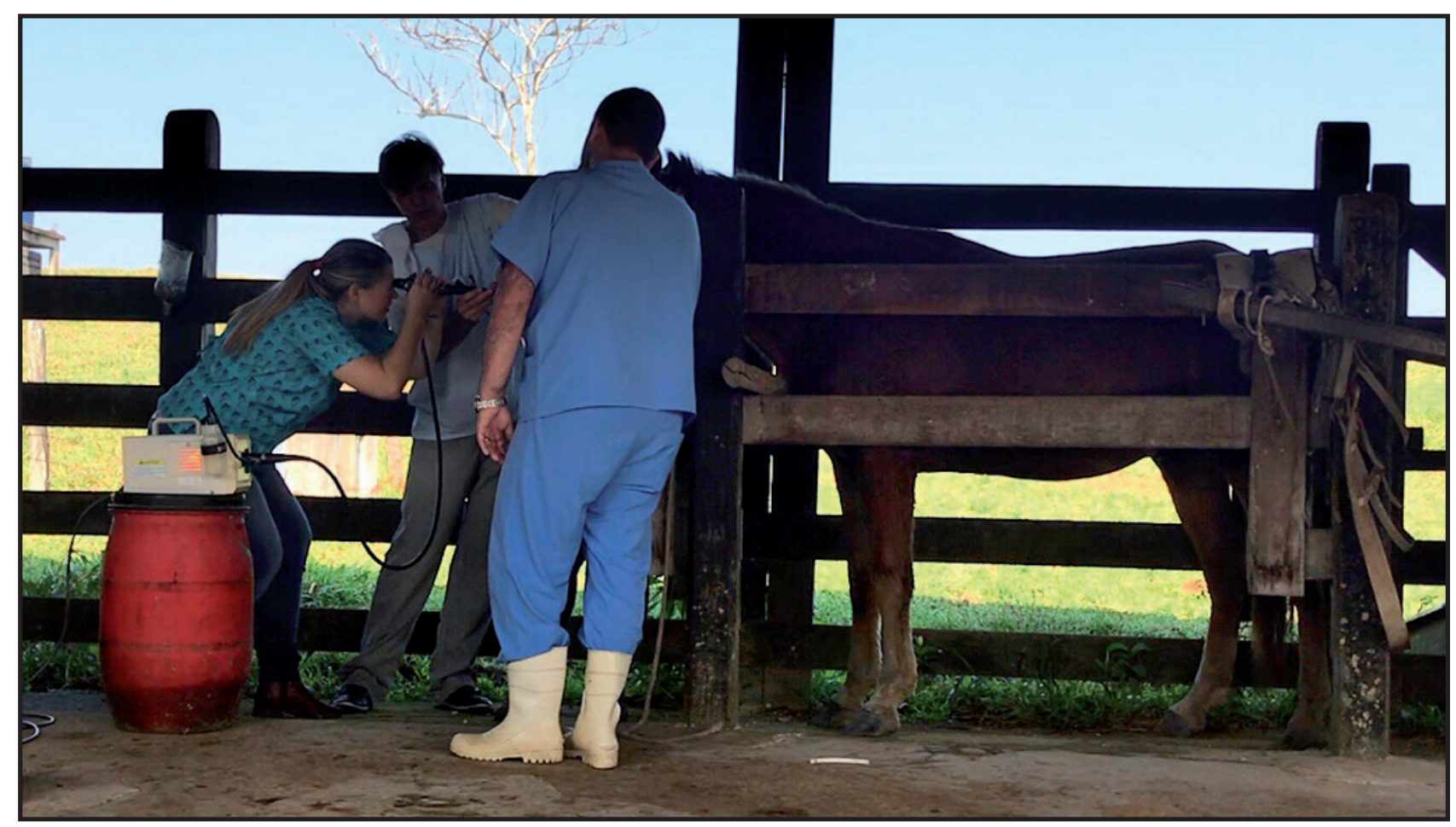

Figure 3. Tracheobronchoscopic exam using an improvised space in the cattle management structure.

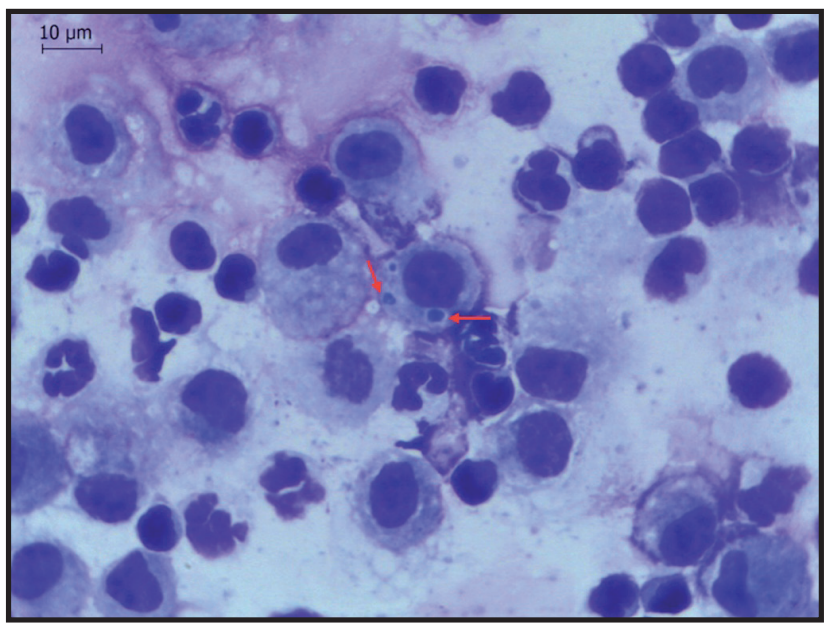

Figure 4. BALF cytology. Aqueous Romanowsky-Giemsa stain. Cytopathological features compatible with severe asthma syndrome. Note the presence of neutrophilic infiltrate and phagocytized yeast in macrophage (arrowhead) $[\mathrm{Bar}=10 \mu \mathrm{m}]$.

Due to the persistent clinical manifestation of SEA over the years - and not only during summer seasons - in animals that were never stabled nor fed with hay, we decided to adopt the nomenclature Equine Pasture Asthma [17]. As far as it is known, this is the first report of Severe Equine Asthma in Rio de Janeiro State in the form that resembles SPAODP where seasonality is not a key aspect as it occurs in the Northern Hemisphere, where the majority of SPAODP cases are seen [7-9,14,23,25,30]. Therefore, we consider that the term Equine Pasture Asthma is more appropriate to describe the observed

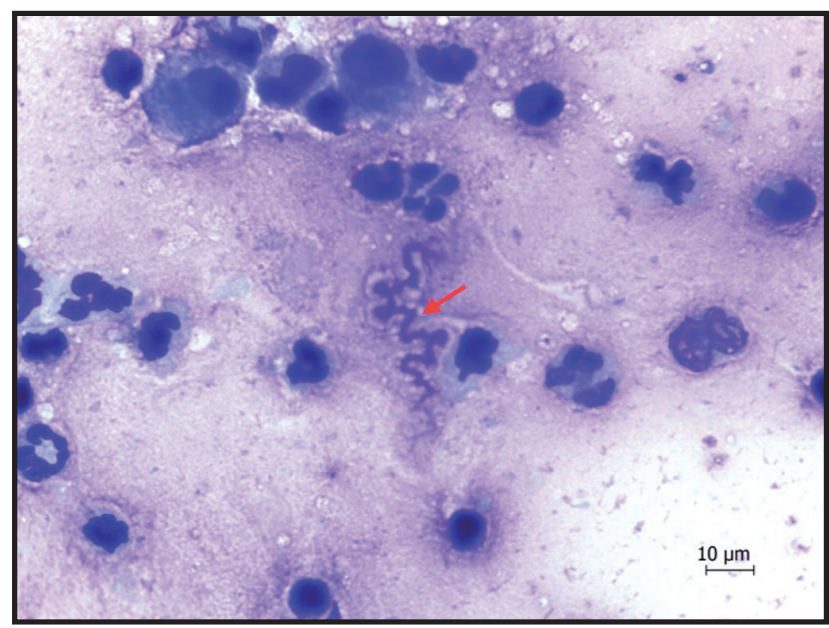

Figure 5. BALF cytology. Aqueous Romanowsky-Giemsa stain. Cytopathological features compatible with severe asthma syndrome. Note the presence of Curschmann's spiral (arrowhead) [Bar=10 $\mu \mathrm{m}]$.

clinical setting in the horses presented here. As stated by other authors [3,27], different nomenclatures for equine asthma should be avoided in order to facilitate diagnosis. Cases of SPAOPD have been described in the Northern Hemisphere as occurring during the summer, between the months of May to July, when temperatures ranged from $17^{\circ} \mathrm{C}$ to $30^{\circ} \mathrm{C}$, with remission of clinical signs by the winter [7]. This same predisposing climate conditions are found in the Rio de Janeiro State throughout the year, where temperatures are mild and solar incidence is high enough to rise the body temperature 
of animals that are maintained at pasture. Specifically in Rio Bonito, where the cases occurred, there is no seasonality between summer and winter. Over the last years, annual temperatures ranged from $17^{\circ} \mathrm{C}$ to $31^{\circ} \mathrm{C}$, and rarely below $15^{\circ} \mathrm{C}$ or above $35^{\circ} \mathrm{C}$. Additionally, the climate of Rio Bonito is mostly extremely humid, with oppressive or muggy days [31].

It has been suggested that the sum of climatic factors (high temperature and humidity) and aeroallergen concentrations in ambient air can worsen the clinical signs of horses with severe equine asthma during disease exacerbations, owing to impaired lung function [5]. It seems that pollens have been implicated as triggers for clinical manifestations of SPAOPD and could act as nonspecific irritants for the reactive airways of affected horses in a continuous basis [7]. In our case report, the presence of a perennial pasture could have contributed to the amount of irritants in ambient air.

Regarding the treatment, a change of environment was advised to both animals. As suggested in the literature [7], the removal of affected horses from the pathogenic environment should be prompt even if the triggering agents or their mechanisms were not yet understood. Our cytological findings included free and phagocytized yeasts (Figure 4) in BALF slide, which is evidence that could be correlated to the perennial pasture where the animals were exposed to. Nevertheless, in our case, stabling or transferring the animals to a different pasture were not possible, so the allergenic stimulus persisted.

The prescribed medication relieved clinical manifestations, however, respiratory signs returned once medication was discontinued. Medical treatment followed the basis of therapeutics for inflammatory pulmonary diseases combining corticosteroids and bronchodilators [29]. Triamcinolone acetonide was indicated on this affection since a single dose is sufficient for a prolonged effect of 3 to 5 weeks [12], facilitating management and reducing veterinary visits.

Administration of omega-3 polyunsaturated fatty acids (PUFAs), especially DHA, were prescribed as a daily feed supplement since long-chain omega-3 PUFAs act directly and indirectly by reducing the arachidonic acid, which leads to less substrate availability for the synthesis of proinflammatory eicosanoids [6]. Additional roles of omega-3 PUFAs in inflammation include decreased activation of nuclear factor kappa- $\beta$, which reduces generation of inflammatory cytokines such as tumour necrosis factor- $\alpha$ (TNF- $\alpha$ ), interleukin-1 $\beta$ (IL-1 $\beta$ ), IL-6, IL-8, and the expression of adhesion molecules [20]. In one report, the use of Omega-3 PUFA supplementation for 2 months resulted in a significant decrease in the relative proportion of neutrophils in the BALF [26].

The prescribed treatment for the horses of Rio Bonito was based in the current veterinary standards, aiming at minimizing clinical signs and restore respiratory function. Despite our clinical recommendation to reallocate the animals to another pasture, this was not feasible and treatment was discontinued by the owner due to its costs. Therefore, further evaluations of the patients and response to therapy could not be done and the decision to retire the animals from farm work was the most suitable outcome to preserve their welfare.

Some difficulties for examining and collecting samples were experienced in this case report, since the horses were on a distant farm, where the structure for examination was not so suitable to restrain the patients. The animals were not very docile during the clinical procedure, no daily monitoring was possible for treatment follow-up, and medication was exclusively administered by a farm employee. This is the reality of most herds maintained at pasture in Brazil, where the extensive and semi-extensive systems are predominant.

In conclusion, these two cases had documented evidence of a chronic respiratory condition compatible with what is described in literature as Equine Pasture Asthma but without the seasonal summer factor. The occurrence of a respiratory disease with such manifestations presents as a warning to other possible cases that might be unnoticed in equine herds in Brazil and in similar climates.

\section{MANUFACTURERS}

${ }^{1}$ Boehringer Ingelheim. Itapecerica da Serra, SP, Brazil.

${ }^{2}$ Vetnil Ind. e Com. de Produtos Veterinários Ltda. Louveira, SP, Brazil.

${ }^{3}$ União Química Farmacêutica Nacional S.A. Embu-Guaçu, SP, Brazil.

${ }^{4}$ Olympus Corporation. Tokyo. Japan.

${ }^{5}$ Smiths Medical International Ltd. Minneapolis, MN, USA.

${ }^{6}$ Zoetis Indústria de Produtos Veterinários Ltda. Guarulhos, SP, Brazil.

${ }^{7}$ Fort Dodge Saúde Animal. Campinas, SP, Brazil.

${ }^{8}$ Laboratório Bravet Ltda. Rio de Janeiro, RJ, Brazil.

${ }^{9}$ Wescor Inc. Logan, UT, USA.

${ }^{10}$ Merck Brasil. Rio de Janeiro, RJ, Brazil.

${ }^{11}$ Holliday-Scott S.A. Buenos Aires, Argentina.

${ }^{12}$ Inovet. Rio de Janeiro, RJ, Brazil.

Declaration of interest. The authors declare no potential conflicts of interest with respect to the research, authorship and/ or publication of this article. 


\section{REFERENCES}

1 Amaral P.C., Graça F.A.S., Vianna L.F.C.G., Borges J.R.J., Ferreira A.M., Pires N.R. \& Voss C. 1999. Chronic obstructive pulmonary disease in horses of Military Police of Rio de Janeiro State. Revista Brasileira de Ciência Veterinária. 6(2): 77-83.

2 Beech J. 1975. Cytology of tracheobronchial aspirates in horses. Veterinary Pathology. 12(3): 157-164.

3 Bond S., Léguillette R., Richard E.A., Couetil L., Lavoie J.P., Martin J.G. \& Pirie R.S. 2018. Equine asthma: Integrative biologic relevance of a recently proposed nomenclature. Journal of Veterinary Internal Medicine. 32: 20882098.

4 Bright L.A., Dittmar W., Nanduri B., McCarthy F.M., Mujahid N., Costa L.R., Burgess S.C. \& Swiderski C.E. 2019. Modeling the pasture-associated severe equine asthma bronchoalveolar lavage fluid proteome identifies molecular events mediating neutrophilic airway inflammation. Veterinary Medicine: Research and Reports. 10: 43-63.

5 Bullone M., Murcia R.Y. \& Lavoie J.P. 2016. Environmental heat and airborne pollen concentration are associated with increased asthma severity in horses. Equine Veterinary Journal. 48: 479-484.

6 Calder P.C. 2006. n-3 Polyunsaturated fatty acids, inflammation, and inflammatory diseases. The American Journal of Clinical Nutrition. 83(6): 1505S-1519S.

7 Costa L.R.R., Johnson J.R., Baur M.E. \& Beadle R.E. 2006. Temporal clinical exacerbation of summer pastureassociated recurrent airway obstruction and relationship with climate and aeroallergens in horses. American Journal of Veterinary Research. 67(9): 1635-1642.

8 Costa L.R.R., Johnson J.R. \& Swiderski C.H. 2016. Managing Summer Pasture-Associated Obstructive Pulmonary Disease, an Asthma-like Disease of Horses. The American Association of Equine Practitioners. [Editorial]. Disponível em: $<$ https://aaep.org/horsehealth/managing-summer-pasture-associated-obstructive-pulmonary-disease-asthma-diseasehorses $>$.

9 Costa L.R.R., Seahorn T.L., Moore R.M., Taylor H.W., Gaunt S.D. \& Beadle R.E. 2000. Correlation of clinical score, intrapleural pressure, cytologic findings of bronchoalveolar fluid, and histopathologic lesions of pulmonary tissue in horses with summer pasture-associated obstructive pulmonary disease. American Journal of Veterinary Research. 61(2): 167-173.

10 Couetil L.L., Cardwell J.M., Gerber V., Lavoie J.P., Léguillette R. \& Richard E.A. 2016. Inflammatory Airway Disease of horses: revised Consensus Statement. Journal of Veterinary Internal Medicine. 30: 503-515.

11 Couetil L.L. \& Thompson C.A. 2020. Airway diagnostics. Veterinary Clinics of North America: Equine Practice. 36(1): 87-103.

12 Davis E. \& Rush B.R. Respiratory disease in the geriatric equine patient. 2006. In: Bertone J. (Ed). Equine Geriatric Medicine and Surgery. St. Louis: Saunders Elsevier, pp.179-192.

13 Davis K.U. \& Sheats M.K. 2019. Bronchoalveolar lavage cytology characteristics and seasonal changes in a herd of pastured teaching horses. Frontiers in Veterinary Science. 6: 74.

14 Dixon P.M. \& McGorum B. 1990. Pasture associated seasonal respiratory disease in 2 horses. Veterinary Record. 126(1): 9-12.

15 Freeman K.P. \& Roszel J.F. 1997. Equine cytology patterns in respiratory conditions of noninfectious or unknown origin. Compendium on Continuing Education for the Practising Veterinarian - North American Edition. 19(6): 755763.

16 Fernandes W.R., Morr E., Lopes L.C.L.C. \& Baccarin R.Y.A. 2006. Estudo retrospectivo de 26 casos clínicos de obstrução aérea recorrente (OAR) em cavalos (1997-2004). Veterinária e Zootecnia. 13(2): 173-181.

17 Ferrari C.R., Cooley J., Mujahid N., Costa L.R., Wills R.W., Johnson M.E. \& Swiderski C.E. 2017. Horses with pasture asthma have airway remodeling that is characteristic of human asthma. Veterinary Pathology. 55(1): 144-158.

18 Gerber V., Straub R., Marti E., Hauptman J., Herholz C., King M., Imhof A., Tahon L. \& Robinson N.E. 2004. Endoscopic scoring of mucus quantity and quality: observer and horse variance and relationship to inflammation, mucus viscoelasticity and volume. Equine Veterinary Journal. 36(7): 576-582.

19 Hewson J. \& Viel L. 2002. Sampling, microbiology and cytology of the respiratory tract. In: Lekeux P. (Ed). Equine Respiratory Diseases. Ithaca: International Veterinary Information Service, pp.1-12.

20 Kang J.X. \& Weylandt K.H. 2008. Modulation of inflammatory cytokines by omega-3 fatty acids. In: Quinn P.J. \& Wang X. (Eds). Lipids in Health and Disease. Dordrecht: Springer, pp.133-143. 
21 Lessa D.A.B., Machado C.H., Duarte C.S., Wachholz L., Lima J.R.P.A. \& Fernandes W.R. 2005. Lower respiratory tract diseases in riding horses in Rio de Janeiro: prevalence, clinical and laboratory aspects. Revista Brasileira de Ciência Veterinária. 12(1-3): 77-83.

22 Lessa D.A.B., Mori E., Viana E.B., Santos O.J., Moreira J.F.E. \& Fernandes W.R. 2007. Lavado broncoalveolar em eqüinos: revisão de literatura parte 2: achados citológicos. Arquivos de Ciências Veterinárias e Zoologia da UNIPAR. 10(1): 31-38.

23 Mair T.S. 1996. Obstructive pulmonary disease in 18 horses at summer pasture. Veterinary Record. 138: 89-91.

24 Marinkovic D., Aleksic Kovacevic S. \& Plamenac P. 2007. Cellular basis of chronic obstructive pulmonary disease in horses. International Review of Cytology. 257: 213-247.

25 McGorum B.C. \& Dixon P.M. 1999. Summer pasture associated obstructive pulmonary disease (SPAOPD): an update. Equine Veterinary Education. 11: 121-123.

26 Nogradi N., Couetil L.L., Messick J., Stochelski M.A. \& Burgess J.R. 2015. Omega-3 fatty acid supplementation provides an additional benefit to a low-dust diet in the management of horses with chronic Lower Airway Inflammatory Disease. Journal of Veterinary Internal Medicine. 29: 299-306.

27 Pirie R.S., Couetil L.L., Robinson N.E. \& Lavoie J.P. 2016. Equine asthma: An appropriate, translational and comprehendible terminology? Equine Veterinary Journal. 48: 403-405.

28 Rossi H., Virtala A.M., Raekallio M., Rahkonen E., Rajamäki M.M. \& Mykkänen A. 2018. Comparison of tracheal wash and bronchoalveolar lavage cytology in 154 horses with and without respiratory signs in a referral hospital over 2009-2015. Frontiers in Veterinary Science. 5: 61.

29 Rush B. \& Mair T. 2004. Non-infectious pulmonary diseases and diagnostic techniques. In: Rush B. \& Mair T. (Eds). Equine Respiratory Diseases. Oxford: Blackwell Science Ltd., pp.187-232.

30 Seahorn T.L., Groves M.G., Harrington K.S. \& Beadle R.E. 1996. Chronic obstructive pulmonary disease in horses in Louisiana. Journal of the American Veterinary Medical Association. 208(2): 248-251.

31 WeatherSpark. 2020. Cedar Lake Ventures Inc. Average Weather in Rio Bonito. 2020. Disponível em: <https:// weatherspark.com/y/30654/Average-Weather-in-Rio-Bonito-Brazil-Year-Round>.

32 Zinkl J.G. 2002. Lower respiratory tract. In: Cowel R.L. \& Tyler R.D. (Eds). Diagnostic Cytology and Hematology of the Horse. St Louis: Mosby, pp.73-86. 